\title{
Nano-encapsulation of sweet basil essential oil based on native gums and its application in controlling the oxidative stability of Kilka fish oil
}

\author{
Sahar Aboutalebzadeh ${ }^{1}$, reza esmaeilzadeh kenari ${ }^{1}$, and Ali Jafarpour ${ }^{2}$ \\ ${ }^{1}$ Affiliation not available \\ ${ }^{2}$ Danmarks Tekniske Universitet
}

May 10, 2021

\begin{abstract}
In the first section of this study, the effects of two different extraction methods on the efficiency and chemical composition and antioxidant activity were compared. Extraction efficiency of supercritical fluid was significantly higher than distillation of water. The results showed that antioxidant activity increased by increasing the concentration of the essential oil. In the second part of the study, to evaluate the impact of various walls, Lepidium sativum (LS), Lepidium perfoliatum (LP) and a combination of both (LP/LS)were used for nano-encapsulation essential oil of basil by freeze-drying. Nanoencapsulate powder was evaluated regarding efficiency, particle size, PDI, Zeta poteintial,SEM, viscosity, Brix,pH, density.humidity, aw and FTIR. In the third part, essential oil of basil in free mode at Level $1 \%, 5 \%$ and $20 \%$ and in encapsulated at the level of $2 \%$ and TBHQ at $0.01 \%$ added to Kilka oil without antioxidants and then the samples were place in an oven at $60{ }^{\circ} \mathrm{C}$ for 16 days. Storage stability of kilka oil regarding peroxide, thiobarbituric and color were analyzed. The results showed that basil essential oil had antioxidant activity and reduced the oxidation process, and also nanocapsule essential oil (especially with a coating of LP gum) showed better antioxidant activity than free essential oil, so that its antioxidant activity is competitive with TBHQ synthetic antioxidants. Finally, we can conclude that it is possible to substitute synthetic antioxidants by natural ones like olive leaf phenolic compounds but we have to apply some forms of encapsulation techniques in order to protect their properties.
\end{abstract}

\section{Hosted file}

Manuscript.pdf available at https://authorea.com/users/413013/articles/521479-nanoencapsulation-of-sweet-basil-essential-oil-based-on-native-gums-and-its-applicationin-controlling-the-oxidative-stability-of-kilka-fish-oil

\section{Hosted file}

Figure.pdf available at https ://authorea.com/users/413013/articles/521479-nano-encapsulationof-sweet-basil-essential-oil-based-on-native-gums-and-its-application-in-controllingthe-oxidative-stability-of-kilka-fish-oil

\section{Hosted file}

Tables.pdf available at https ://authorea.com/users/413013/articles/521479-nano-encapsulationof-sweet-basil-essential-oil-based-on-native-gums-and-its-application-in-controllingthe-oxidative-stability-of-kilka-fish-oil 